\title{
High-grade urothelial CARCinoma, plasmacytoid VARIANT, OF THE RENAL PELVIS WITH OSTEOCLAST-LIKE GIANT CELLS AND FOCAL RHABDOID FEATURES
}

\author{
Naoto Kuroda ${ }^{1}$, Takushi Naroda ${ }^{2}$, Masato Tamura 2 , Delia Perez-Montiel ${ }^{3}$, Michal Michal ${ }^{4}$, \\ ONDREJ Hes ${ }^{4}$
}

\author{
${ }^{1}$ Department of Diagnostic Pathology, Kochi Red Cross Hospital, Kochi, Japan \\ ${ }^{2}$ Department of Urology, Kochi Red Cross Hospital, Kochi, Japan \\ ${ }^{3}$ Department of Pathology, National Institute of Cancer of Mexico, Mexico City, Mexico \\ ${ }^{4}$ Department of Pathology, Charles University in Prague, Faculty of Medicine in Pilsen, Pilsen, Czech Republic
}

\begin{abstract}
In this article, we present a rare case of renal pelvic carcinoma. The imaging examination of a 75-year-old Japanese man disclosed the left renal pelvic tumor. The histological examination showed the finding of predominant undifferentiated discohesive mononuclear cells with abundant osteoclast-like giant cells and a minor component of papillary urothelial carcinoma. Rhabdoid morphology was focally seen. Immunohistochemically, mononuclear cells were focally positive for thrombomodulin and showed a high MIB-1 index, whereas osteoclast-like giant cells were positive for CD68. Urologists should bear in mind that a rare association of high-grade urothelial carcinoma, plasmacytoid variant, with osteoclast-like giant cells and focal rhabdoid features may occur in the renal pelvis.
\end{abstract}

Key words: renal pelvis, urothelial carcinoma, plasmacytoid, rhabdoid, osteoclast-like giant cells.

\section{Introduction}

Urothelial carcinoma, plasmacytoid variant often occurs in urinary bladder, but there are only two cases of urothelial carcinoma, plasmacytoid variant, arising from the renal pelvis $[1,2]$. On the one hand, there are only six cases of urothelial carcinoma of the renal pelvis with rhabdoid features $[1,3,4]$. On the other hand, there are only seven cases of renal pelvic carcinoma with non-neoplastic osteoclast-like giant cells [5-8]. In this article, we report a very rare case of high-grade urothelial carcinoma, plasmacytoid variant, of the renal pelvis with osteoclast-like giant cells and focal rhabdoid features.

\section{Clinical summary and methods}

A 75-year-old Japanese man presented with macrohematuria and consulted the Department of Urology, Kochi Red Cross Hospital. The abdominal com- puted tomography scan disclosed the renal pelvic tumor and urine cytology showed the suspicion of malignancy. Accordingly, left nephro-ureterectomy was undertaken on the basis of the clinical diagnosis of left renal pelvic cancer.

The first level of histological sections obtained from nephro-ureterectomy were cut from formalin-fixed and paraffin-embedded tissue blocks and stained with hematoxylin and eosin. The subsequent levels of tissue sections were cut for immunostaining and stained with Ventana Benchmark XT autostainer (Ventana Medical Systems, Tucson, AZ). The primary antibodies against cytokeratin 7 (OV-TL 12/30, 1 : 800, DAKO, Glostrup, Denmark), cytokeratin 20 (Ks 20.8, $1: 200$, DAKO, Glostrup, Denmark), thrombomodulin (1009, 1 : 200, DAKO, Glostrup, Denmark), CD138 (MI15, 1 : 25, DAKO, Glostrup, Denmark), CD68 (KP-1, prediluted, DAKO, Glostrup, Denmark) and Ki-67 (MIB-1, 1 : 400, DAKO, Glostrup, Denmark) were employed in the present study. 


\section{Pathological findings}

\section{Macroscopic findings}

A nodular and broad-based tumor measuring $30 \times$ $20 \mathrm{~mm}$ was observed in the left pelvis (Fig. 1). Hemorrhage was focally seen, but necrosis was absent.

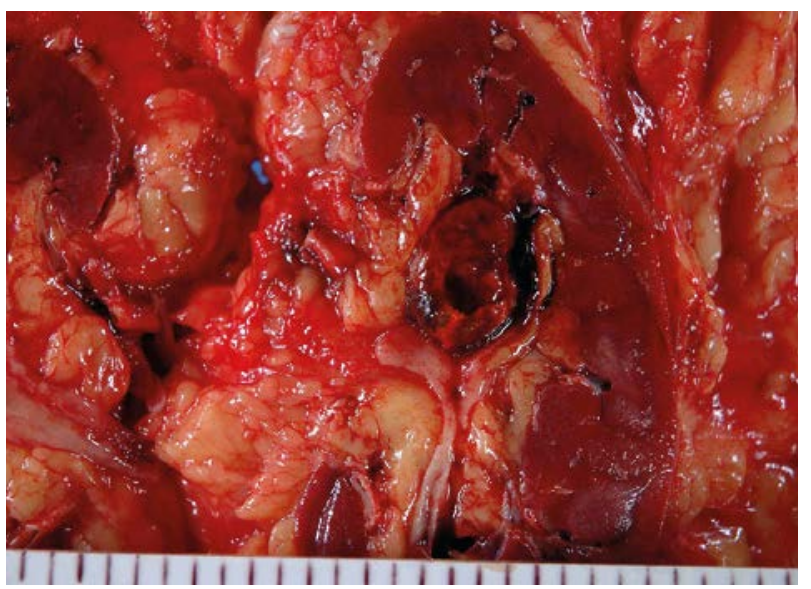

Fig. 1. Macroscopic findings. The broad-based tumor protrudes into the lumen of renal pelvis
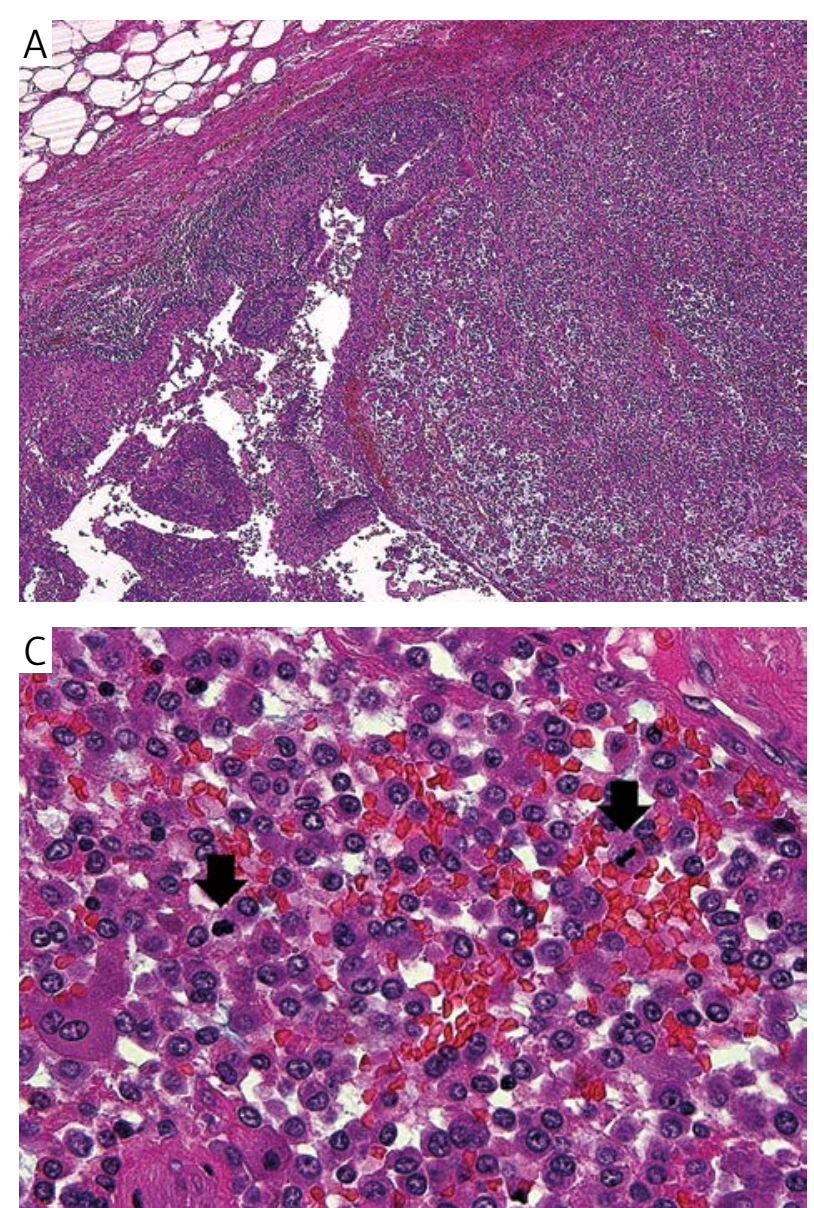

\section{Microscopic findings}

Histologically, non-invasive papillary urothelial carcinoma and urothelial carcinoma in situ were identified in the superficial layer of the tumor as the minor component (Fig. 2A). The tumor predominantly consisted of discohesive mononuclear cells with cytologic atypia, namely plasmacytoid features and abundant osteoclast-like giant cells lacking cytologic atypia (Fig. 2B) and invading the muscle layer. Plasmacytoid cells focally exhibited mitotic activity (Fig. 2C). Some neoplastic cells with deeply eosinophilic cytoplasm and eccentric nuclei, namely rhabdoid cells, were also noted (Fig. 2D).

\section{Immunohistochemical findings}

The discohesive mononuclear cells were diffusely positive for vimentin, focally positive for cytokeratin 7 , CD68 and thrombomodulin (Fig. 3A), but negative for cytokeratin 20 and CD138. Vimentin detected the aggregates of intermediate filaments in rhabdoid cells (Fig. 3B). Osteoclast-like giant cells showed diffuse labeling for CD68 (Fig. 3C). The MIB-1 index of mononuclear cells was $20 \%$, but that of osteoclast-like giant cells was $0 \%$ (Fig. 3D).
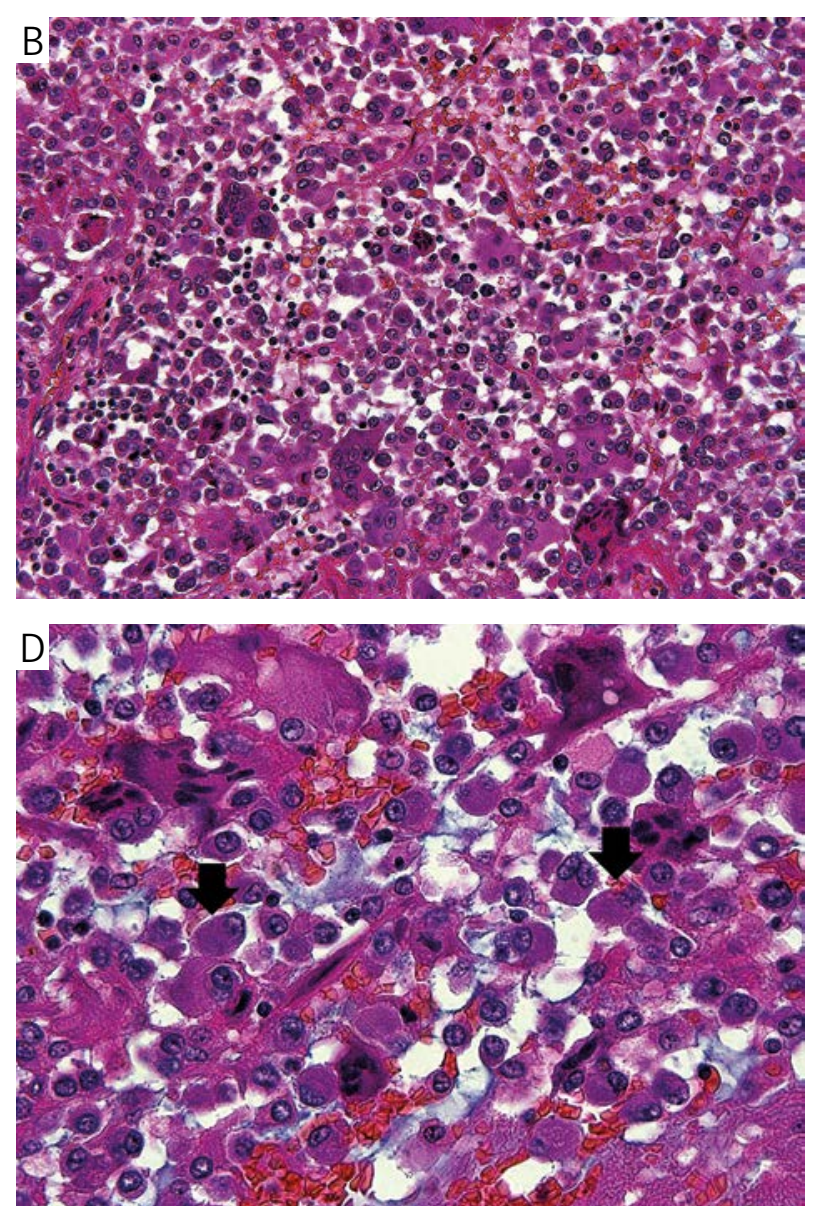

Fig. 2. Microscopic findings. A) Papillary growth of urothelial carcinoma is seen. B) Monotonous proliferation of mononuclear cells with several osteoclast-like giant cells is observed. C) Mitotic activity is seen in mononuclear tumor cells (arrows). D) Rhabdoid features containing eosinophilic inclusion are identified (arrows) 

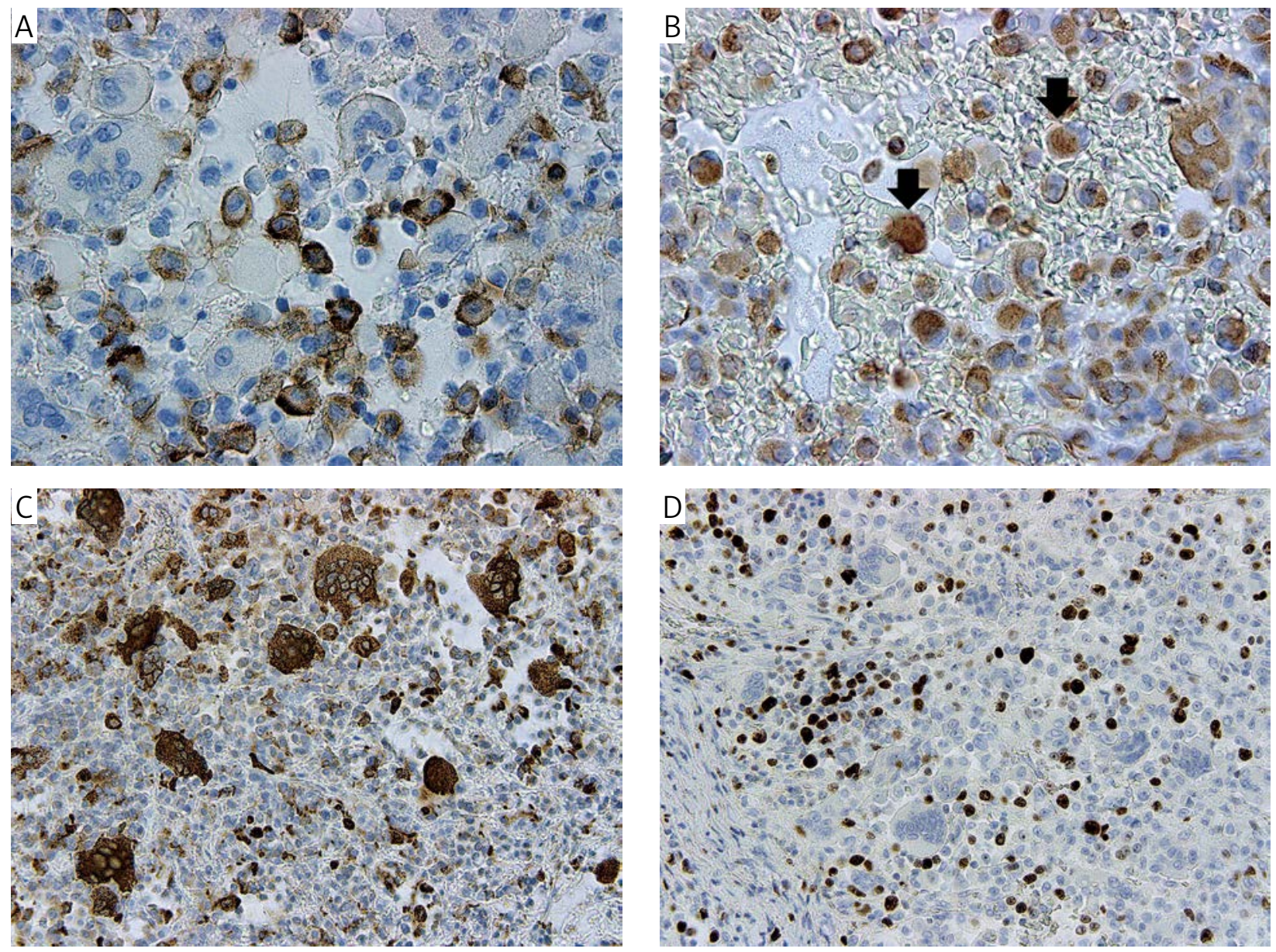

Fig. 3. Immunohistochemical findings. A) The mononuclear neoplastic cells are focally positive for thrombomodulin. B) Vimentin immunohistochemistry shows aggregates of intermediate filaments in rhabdoid cells (arrows). C) Multinucleated giant cells are diffusely positive for CD68. D) Mononuclear neoplastic cells show labeling of $20 \%$ but giant cells are completely negative

\section{Discussion}

The appearance of giant cells in high-grade urothelial carcinoma has been previously reported. Osteoclast-like giant cells are generally considered to be a stromal reaction [5-8]. However, some authors consider that giant cells are a neoplastic component $[9,10]$. Non-neoplastic giant cells should be strictly distinguished from the giant cell variant of urothelial carcinoma. In this distinction, the immunohistochemistry of CD68, cytokeratin 7, thrombomodulin and $\mathrm{Ki}-67$ is helpful. The giant cell component of urothelial carcinoma exhibits positivity for cytokeratin 7 and thrombomodulin and a high index of Ki-67, whereas non-neoplastic giant cells show reactivity for CD68 and a zero to minimal index of Ki-67.

To the best of our knowledge, there are only two reports and six reports, respectively, on the plasmacytoid variant and rhabdoid features of urothelial carcinoma [1-4]. In a large series of high-grade urothelial carcinoma, there is no case with high-grade urothelial carcinoma having plasmacytoid and rhabdoid features [1]. Although this association in the renal pelvis is very rare, a close relationship between both features is suggested as a discohesive variant [11].

In conclusion, we report a rare case of high-grade urothelial carcinoma of the renal pelvis, plasmacytoid variant, with osteoclast-like giant cells and focal rhabdoid features. We can also designate this tumor as urothelial carcinoma similar to giant cell tumor of bone according to the textbook of Uropathology (SAUNDERS, ELSEVIER) edited by Ming Zhou et al. Urologists should recognize that such a tumor may occur in the renal pelvis.

\section{The authors declare no conflict of interest.}

\section{References}

1. Perez-Montiel D, Wakely PE, Hes O, et al. High grade urothelial carcinoma of the renal pelvis: clinicopathological study of 108 cases with emphasis on unusual morphologic variant. Mod Pathol 2006; 19: 494-503.

2. Keck B, Giedl J, Kunath F, et al. Clinical course of plasmacytoid urothelial carcinoma of upper urinary tract: a case report. Urol Int 2012; 89: 120-122. 
3. Fukumura Y, Fujii H, Mitani K, et al. Urothelial carcinoma of the renal pelvis with rhabdoid features. Pathol Int 2009; 59: 322-325.

4. Shintaku M, Megumi Y, Maekura S. Adenocarcinoma of the renal pelvis with vimentin-positive intracytoplasmic inclusions. Pathol Int 2000; 50: 48-51.

5. Sekido Y, Satoh F, Usui Y, Tsutsumi Y. Sarcomatoid carcinoma of the renal pelvis: a case report. Pathol Int 2000; 50: 562-567.

6. Baydar D, Amin MB, Epstein JI. Osteoclast-rich undifferentiated carcinomas of the urinary tract. Mod Pathol 2006; 19: 161-171.

7. Acikalin MF, Kabukcuoglu S, Can C. Sarcomatoid carcinoma of the renal pelvis with giant cell tumor-like features. Case report with immunohistochemical findings. Int J Urol 2005; 12: 199-203.

8. McCash SI, Unger P, Dillon R, Xiao GQ. Undifferentiated carcinoma of the renal pelvis with osteoclast-like giant cells: a report of two cases. APMIS 2010; 118: 407-412.

9. Molinié V, Pouchot J, Vinceneux P, Barge J. Osteoclast-like giant cell tumor of the renal pelvis associated with papillary transitional cell carcinoma. Arch Pathol Lab Med 1997; 121: 162-166.

10. Borg-Grech A, Morris JA, Eyden BP. Malignant osteoclastoma like giant cell tumour of the renal pelvis. Histopathology 1987; 11: 415-425.

11. Epstein JI, Reuter VE, Amin MB. Histologic variants of urothelial carcinoma. In: Biopsy Interpretation of the Bladder. Epstein JI, Reuter VE, Amin MB (eds.). LWW, Philadelphia, PA 2010; 150-152.

\section{Address for correspondence}

\section{Naoto Kuroda, MD}

Department of Diagnostic Pathology

Kochi Red Cross Hospital

Shin-honmachi 2-13-51

Kochi City, Kochi 780-8562, Japan

tel. +81-88-822-1201 ext. 1610

fax $+81-88-822-1056$

e-mail: kurochankochi@yahoo.co.jp 